Japunese Psychologial Reserind

1994, Vol. 36, No. 4, 201-210

\title{
An application of art therapy to education of female art students
}

\author{
KUMIKO MURAYAMA \\ Women's Junior College of Fine Arts, Wada, Suginami-ku. Tokyo 166
}

\begin{abstract}
The present study evaluated a course that attempted to apply art therapy techniques to art education for female students. The Landscape Montage Technique was used to explain the art therapy theory, since its methods of interpretation were well established. The purpose of the nine-session course. "Expressive Training," in which seven pictures were drawn, was to encourage female students, from a psychological point of view, in the pursuit of their careers. First, students reproduced one of the best pictures they had painted in the past. Then. each drew two pictures of her "feelings now." In this step, a focusing method was used to deal with the students" current problems. Finally, they drew an image of their future work. The Aesthetic Interest Test, a Self-Esteem Scale, and the K-H-T-P drawings were administered at the beginning and the end to evaluate the effects of the course, and the test scores generally improved. Additionally, students' impressions of their own works, rated along sixteen scales, showed that their pictures were seen as generally feminine, warm, bright, curvy and soft.
\end{abstract}

Key words: art therapy, female art students, expressive training.

Art therapy is generally used in the clinical psychology field for testing and for treatment of mental, social, or behavioral disorders. Art therapy techniques are not only used as a diagnostic tool to evaluate mental conditions; they also can have positive effects on treatment, helping people reveal their thought processes and giving them the mental freedom to gain insights about themselves. In other words, emotions released through powerful artistic experiences can open the door to the mind.

In this study, art therapy techniques were applied to art education as a method of creativity training. The subjects were average female college students whose areas of specialization were in the arts. Instead of "Art therapy" however, this training course was called "Expressive Training." Caplan (1989) used the term "Expressive Training" to refer to a technique for improving mother-daughter relationships. Compared with that of

1 This study was supported by the research foundation of Women's Junior College of Fine Arts.
"Assertiveness Training," which has been developed in conjunction with the feminist movement, the image of "Expressive Training" is mere gentle and sophisticated. Assertiveness is a necessary first step in opening the way to freedom of expression. The next step for women is to learn methods of persuasion, that will make their lives more fruitful. More and more, creative means of expression are necessary to young women, who wish to build social lives and careers. Therefore, the author chose the title "Expressive Training" for this study.

A global purpose of this study is to help female art students have successful careers. Here, "success" is nearly the same as that of "self-actualization," "success" does not mean becoming rich and famous. In this project, we pursue the basic values of beauty and truth those are the purpose of female art student's self-actualization, art therapy has the power to help those in despair, even of psychologically healthy young women. It can increase the well-being.

This experiment had three main purposes. 
1. This experimental course was used as a device for teaching general psychology, with the material adapted to the interests and aptitudes of the students. The author had often thought that the ordinal lecture system did not always appeal to female art students. While art therapy is a limited subject, it is based on multiple psychological theories, such as psychoanalysis, behaviorism, humanistic psychology, cognitive psychology, the study of images and creative theory. During the course on this selected topic, the subjects enjoy drawing and learning about psychology at the same time.

2. The course provides chances for the subjects to draw in a free situation, without critiques or evaluations. "Expressive Training" is not art education. Rather, it is concerned with the motivational side of creative behavior. For the purpose of supporting students in the pursuit of careers for make self awareness, this project could provide a psychological point of view on coping with life problems.

3. Becoming an art therapist is a future career option for art students. Even if they do not choose such a career, but become teachers of amature artists, for example, it will be helpful for them to be able to understand how emotions, personality and psychological problems are projected into art works.

In this study, the effects of the course, which was designed for these specific purposes, were evaluated.

\section{Methods}

\section{Subjects}

Three hundred and six female students at an art college and a junior art college participated in this study.

\section{Procedures}

The course consisted of nine weekly sessions. Seven pictures were drawn during the course. The Aesthetic Interests Test
(Lindauer, 1981), a Self-Esteem Scale (Rosenberg, 1965), and the Kinetic-HouseTree-Person drawings (K-H-T-P, Burns, 1987) were taken twice at the beginning and end of the course, to determine the effects of the training. The Landscape Montage Technique (LMT, Nakai, 1984) was used to explain the theory and reading methods of art therapy.

Activities specially devised for this course were the drawing of images of the past, present and future. For the Present drawing, a focusing method (Gendlin, 1978) was applied. There were two reasons for choosing these activities. First, they were devised to support the future careers of female art students. As a method of image training, the follwing four steps can be recommended to help meet the challenges of life.

1. Relaxation: Whenever necessary, it is possible to get into relaxed mental state for this purpose, at the beginning of every session a simple relaxation technique was introduced. Subjects relaxed their neck and shoulders, concentrated on their breathing and counted ten deep breaths, each time saying "One."

2. Images of past success: The instruction was, "Remember the most impressive picture you had drawn in the past, and represent it now." The memory of success helps bring about future success. In this class, subjects remembered their past drawings. This activity might connected subjects' memories of success.

3. Images of the future: People can realize only what they can imagine. Therefore, subjects were encouraged to depict an image of their future work.

4. Methods for dealing with problems in the present: In this part of the course, a focusing method was introduced to help students learn to experience and deal with their problems more effectively. 
There was an additional reason for selecting activities related to the past, present and future. From the developmental psychological point of view, self-recognition as an existence living on time scales is constructed during adolescence. "Time" has two meanings: one is history, and the other is an individual's life span. The themes of this course were related to the latter. The relationships between causes and effects of life events can be understood by adolescents in the "formal operation" period described in Piaget's cognitive development theory. Recognitiion of "necessity" is a distinctive feature of this stage.

Moreover, adolescents spontaneously note unconscious motives for their behavior (Selmen, 1980). Students in this course seemed to have a strong interest in looking for unconscious expression in their own pictures. For this reason, the course was very attractive to them.

The materials provided to students were white sheets of B4-size paper and twenty color crayons. The nine sessions were as follows:

1. Subjects took the Aesthetic Interests Test and completed a Self-Esteem Scales as a pre-course check.

2. Subjects made K-H-T-P drawings. These drawings, based on A. H. Maslow's five-level motivation theory, were also used to evaluate students' mental changes during the course. The top level of Maslow's motivation structure is self-actualization, which seems an appropriate goal for young subjects who wish to become creators. This session was called $1 \mathrm{st}$ K-H-T-P.

3. Subjects drew the LMT pictures in which they successfully depicted the following images; river, mountain, field, road, house, tree, person, animal, flower, stone, and something that they chose.

4. In the former part of this session, subjects were asked to write down their memo- ries of success. In the latter part, they were instructed to remember the most impressive picture they had drawn in the past and reproduce it.

5. Subjects learned the first focusing method. They practiced an orthodox focusing technique using words and inner images. Oral instruction of the focusing technique was as follows: "Think about yourself now. You may be feeling happiness or distress. You also have feelings about your life. Relax and feel your life now. Don't get into your problems. Separate yourself from them and just put them aside. How do you think of yourself? Focus on your feelings."

6. Subjects practiced focusing to discover their present feelings, and then they expressed the feelings in pictures.

7. Subjects repeated the focusing experiment and represented their feelings in pictures once again.

8. First, subjects wrote down their hopes for their future. Next, they were instructed to sketch images of the works that they wanted to produce in the future.

9. Subjects repeated the 2 nd K-H-T-P, the Aesthtic Interests Test, and a Self-Esteem Scales, as a post-course check. Then they wrote down their opinions of this course.

\section{Results}

Figures 1 and 2 are samples of pictures drawn by a student in the course. Figure 1 shows 1st K-H-T-P, LMT, and Past drawing samples "subject A." Figure 2 shows 1st Focusing, 2nd Focusing, Future, and 2nd KH-T-P drawing by the same subject. She was an art student specializing in painting, and her drawing style looked like brush strokes in oil painting. The image in 1 st K-H-T-P is receding, suggesting she might have been depressed at the time. In contrast, her 2 nd $\mathrm{K}$ H-T-P is a more extraverted expression. Her LMT suggests her particular aptitudes. She 
seemed to be interested in drawing landscapes, because she selected a snow-covered mountain as the subject of her past memory drawing. The 1st and 2nd Focusing sessions, freed her images, so that her Future work developed into colorful religious figures.

Subjects were more deeply committed to this class than in the case of the previous one-way lecture style. No students ever "escaped" from class during the experiments. They wrote positive opinions of the art therapy-style lecture, including the use of crayons

a

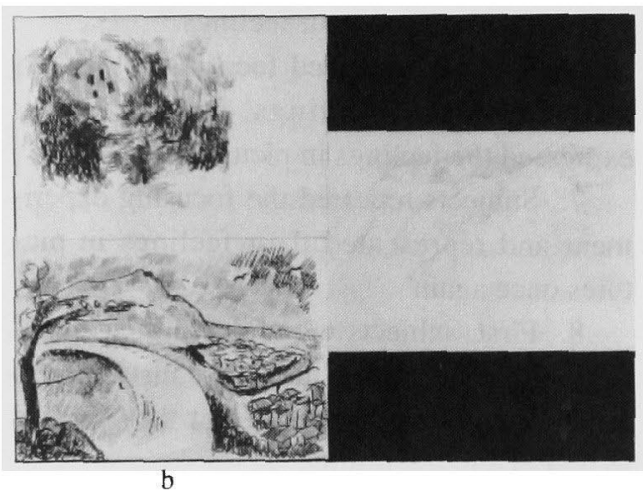

Figure 1. First K-H-T-P (a), LMT (b) and Past (c) drawings of Subject $\mathrm{A}$.

a

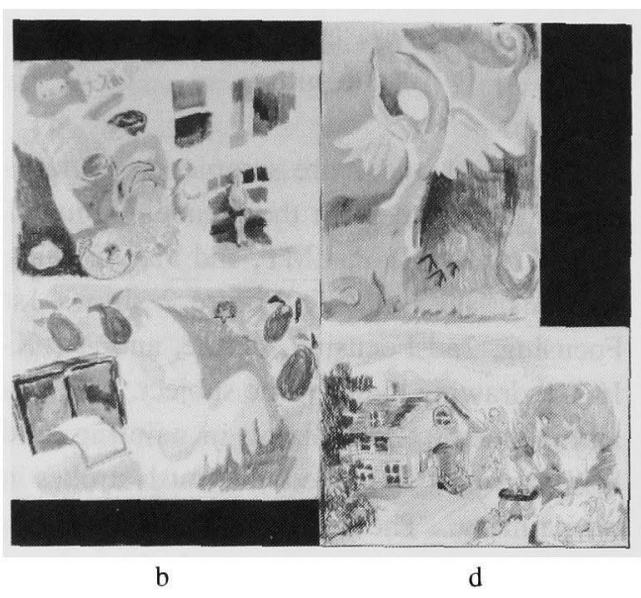

Figure 2. First Focusing (a), 2nd Focusing (b), Future (c) and 2nd K-H-T-P (d) drawings of Subject A. as a medium.

The average score on the first Aesthetic Interest Test was $22.5(S D=5.1)$, and that on the second was $24.7(S D=6.0)$. The " $t$ " value which measured the differences between the two scores was $8.0(F=305, p>.05)$. The second score was generally significantly higher than the first: 200 subjects showed higher scores on the second test than on the first, and 79 subjects showed lower scores on the second. Twenty-seven subjects received the same score on both tests. The percentages of these three groups were significantly different $\left(\chi^{2}=154.5, F=2, p<.01\right)$. The author wishes to add that the average single test score of the 353 students in the classes of the previous year was $22.8(S D=5.1)$. The " $t$ " value between the scores on the previous year's test and those on the first test this year was 0.4 ( $F=645.7$ ) which was not significant; but the " $"$ "value between scores on the previous year's test and this year's second test was 4.5 $(F=602.5, p<.01)$, which showed a significant difference.

The average of the first Self-Esteem Scale scores was $5.2(S D=2.6)$, and that of the second was $5.4(S D=2.7)$. As the " $t$ " value was $1.82(F=305)$, there was no significant difference between the two average scores. However, the number of subjects who had higher scores on the second test was 136; of those who had lower scores was 95; and of those who had same score on both tests was 75 , making the three percentages significantly different $\left(\chi^{2}=19.0, F=2, p<.01\right)$. This meant that Self-Esteem Scores improved slightly during the course.

The lst and 2nd K-H-T-P were analyzed according to Burns' system, which is based on Maslow's five-level motivation theory (Burns, 1987). The drawings-house, tree and person, judged separately according this system, each one, has eight categories-Maslow's five categories and their subcategories (Table 1, Table 2). 
Table 1

Levels of "house," "tree," "person" and "movement" in Ist and 2 nd K-H-T-P and $\chi^{2}$ test values between 1 st and 2 nd K-H-T-P

\begin{tabular}{|c|c|c|c|c|c|c|c|c|}
\hline Levels & lav & lap & $2 \mathrm{ar}$ & $2 a p$ & $3 a v$ & $3 a p$ & 4 & 5 \\
\hline \multicolumn{9}{|l|}{ House } \\
\hline \multirow[t]{2}{*}{ IstK-H-T-P } & 30 & 49 & 48 & 71 & 8 & 39 & 45 & 16 persons \\
\hline & $19.8 \%$ & $16.1 \%$ & $15.7 \%$ & $23.2 \%$ & $2.6 \%$ & $12.8 \%$ & $14.7 \%$ & $5.2 \%)$ \\
\hline \multirow[t]{2}{*}{$2 n d K-H-T \cdot P$} & 48 & 54 & 46 & 76 & 15 & 43 & 16 & 8 persons \\
\hline & $115.7 \%$ & $17.7 \%$ & $15.0 \%$ & $24.8 \%$ & $4.9 \%$ & $14.1 \%$ & $5.2 \%$ & $2.6 \%)$ \\
\hline$\chi^{2}(F=1)$ & $4.8^{*}$ & 0.3 & 0.1 & 0.2 & 2.2 & 0.2 & $15.3 * *$ & 2.8 \\
\hline \multicolumn{9}{|l|}{ Tree } \\
\hline \multirow[t]{2}{*}{ IstK-H-T-P } & 51 & 10 & 37 & 94 & 4 & 48 & 60 & 2 persons \\
\hline & $(16.7 \%$ & $3.2 \%$ & $12.1 \%$ & $30.7 \%$ & $1.3 \%$ & $15.7 \%$ & $19.6 \%$ & $0.7 \%)$ \\
\hline \multirow[t]{2}{*}{ 2ndK-H-T-P } & 60 & 12 & 35 & 84 & 8 & 48 & 55 & 4 persons \\
\hline & $19.6 \%$ & $3.9 \%$ & $11.4 \%$ & $27.5 \%$ & $2.7 \%$ & $15.7 \%$ & $18.0 \%$ & $1.3 \%)$ \\
\hline$\chi(F=1)$ & 0.9 & 0.2 & 0.1 & 0.8 & 1.4 & 0.0 & 0.3 & 0.7 \\
\hline \multicolumn{9}{|l|}{ Person } \\
\hline \multirow[t]{2}{*}{ 1stK-H-T-P } & 28 & 15 & 97 & 18 & 30 & 44 & 61 & 13 persons \\
\hline & $19.2 \%$ & $4.9 \%$ & $31.7 \%$ & $5.9 \%$ & $9.8 \%$ & $14.4 \%$ & $19.9 \%$ & $4.3 \%)$ \\
\hline \multirow[t]{2}{*}{ 2ndK-H-T-P } & 32 & 5 & 108 & 11 & 61 & 22 & 37 & 8 persons \\
\hline & $(10.5 \%$ & $1.6 \%$ & $35.3 \%$ & $3.6 \%$ & $19.9 \%$ & $14.4 \%$ & $12.1 \%$ & $2.6 \%$ \\
\hline$\chi^{2}(F=1)$ & 0.3 & $5.2^{*}$ & 0.9 & 1.8 & $12.4^{* *}$ & 0.0 & $7.0^{* *}$ & 1.2 \\
\hline Movement & Level 1 & Level 2 & \multicolumn{2}{|c|}{ Level 3} & & & & \\
\hline \multirow[t]{2}{*}{ IstK-H-T-P } & 89 & 100 & \multirow{2}{*}{\multicolumn{2}{|c|}{$\begin{array}{l}177 \text { persons } \\
38.2 \% \text { ) }\end{array}$}} & & & & \\
\hline & $(29.1 \%$ & $32.7 \%$ & & & & & & \\
\hline \multirow[t]{2}{*}{$2 n d K-H-T-P$} & 125 & 83 & \multirow{2}{*}{\multicolumn{2}{|c|}{$\begin{array}{l}98 \text { persons } \\
32.0 \%)\end{array}$}} & & & & \\
\hline & $(40.9 \%$ & $27.1 \%$ & & & & & & \\
\hline$\chi^{2}(F=1)$ & $9.3 * *$ & 2.3 & \multicolumn{2}{|c|}{2.6} & & & & \\
\hline
\end{tabular}

Note: asterisk or double asterisk shows that percentages of 1 st and 2 nd K-H-T-P are significantly different, by $p<.01(* *)$ or $p<05\left(^{*}\right)$.

Table 2

Level and size changes between the first and second "house," "tree" and "person" drawings, and changes in movement and color of greenery. $\chi^{2}$ values among three levels and sizes are shown

\begin{tabular}{|c|c|c|c|c|c|c|}
\hline & \multicolumn{3}{|c|}{ Level } & \multicolumn{3}{|c|}{ Size } \\
\hline & down & same & up & $>$ & $=$ & $<$ \\
\hline \multirow[t]{2}{*}{ House } & 133 & 92 & 81 & 116 & 51 & 139 persons \\
\hline & $(43.5 \%$ & $30.1 \%$ & $26.8 \%$ ) & $(37.9 \%$ & $16.7 \%$ & $45.4 \%)$ \\
\hline$\chi^{2}(F=2)$ & $14.7 * *$ & & & $40.8^{* *}$ & & \\
\hline \multirow[t]{2}{*}{ Tree } & 102 & 110 & 94 & 107 & 51 & 148 persons \\
\hline & $(33.3 \%$ & $36.0 \%$ & $30.7 \%)$ & $(35.0 \%$ & $16.7 \%$ & $48.4 \%)$ \\
\hline$\chi^{2}(F=2)$ & 1.3 & & & $46.5^{* *}$ & & \\
\hline \multirow[t]{2}{*}{ Person } & 111 & 106 & 89 & 97 & 103 & 106 persons \\
\hline & $(36.3 \%$ & $34.6 \%$ & $29.1 \%)$ & $(31.7 \%$ & $33.7 \%$ & $34.6 \%)$ \\
\hline$\chi^{2}(F=2)$ & 2.6 & & & 0.4 & & \\
\hline \multirow[t]{3}{*}{ Movement } & & & & Deeper & & \\
\hline & 112 & 117 & 177 & 48 & 73 & 185 persons \\
\hline & $36.6 \%$ & $38.2 \%$ & $57.8 \%$ ) & (15.7\% & $23.9 \%$ & $60.5 \%)$ \\
\hline$\chi^{2}(F=2)$ & $9.3^{* *}$ & & & $104.4^{* *}$ & & \\
\hline
\end{tabular}

Note: ** double asterisk shows that the percentages of three scores are significantly variable, by $p<.01$. 
Table 3

Means and standard deviation scores of semantic differential scales

(Subjects' evaluations of their own pictures.)

\begin{tabular}{|c|c|c|c|c|c|c|c|c|}
\hline & future & original & feminine & dislike & cool & dispersed & curvy & static \\
\hline Ist K-H-T-P & 1.8 & 1.7 & 2.4 & 1.4 & 1.3 & 1.6 & 2.3 & 2.1 \\
\hline$(S D)$ & $(0.8)$ & $(0.7)$ & $(0.7)$ & $(0.6)$ & $(0.6)$ & $(0.7)$ & $(0.7)$ & $(0.9)$ \\
\hline LMT & 1.6 & 1.5 & 2.3 & 1.5 & 1.2 & 1.8 & 2.5 & 2.1 \\
\hline$(S D)$ & $(0.7)$ & $(0.7)$ & $(0.6)$ & $(0.6)$ & $(0.5)$ & $(0.8)$ & $(0.7)$ & $(0.9)$ \\
\hline Past & 1.2 & 1.6 & 2.4 & 1.3 & 1.4 & 1.7 & 2.3 & 2.1 \\
\hline$(S D)$ & $(0.5)$ & $(0.8)$ & $(0.7)$ & $(0.6)$ & $(0.6)$ & $(0.7)$ & $(0.8)$ & $(0.8)$ \\
\hline Ist Focusing & 2.0 & 2.0 & 2.3 & 1.8 & 1.8 & 2.0 & 2.4 & 1.9 \\
\hline$(S D)$ & $(0.5)$ & $(0.7)$ & $(0.6)$ & $(0.8)$ & $(0.7)$ & $(0.8)$ & $(0.7)$ & $(0.8)$ \\
\hline 2nd Focusing & 2.1 & 2.0 & 2.3 & 1.7 & 1.8 & 1.9 & 2.4 & 1.9 \\
\hline$(S D)$ & $(0.5)$ & $(0.7)$ & $(0.6)$ & $(0.7)$ & $(0.7)$ & $(0.8)$ & $(0.7)$ & $(0.9)$ \\
\hline Future & 2.6 & 2.0 & 2.3 & 1.4 & 1.6 & 1.7 & 2.4 & 2.0 \\
\hline$(S D)$ & $(0.7)$ & $(0.8)$ & $(0.7)$ & $(0.6)$ & $(0.7)$ & $(0.8)$ & $(0.7)$ & $(0.8)$ \\
\hline $2 n d K-H-T-P$ & 1.9 & 1.6 & 2.3 & 1.4 & 1.4 & 1.6 & 2.2 & 2.1 \\
\hline \multirow[t]{2}{*}{$(S D)$} & $(0.7)$ & $(0.7)$ & $(0.6)$ & $(0.6)$ & $(0.6)$ & $(0.7)$ & $(0.6)$ & $(0.8)$ \\
\hline & deep & stable & dark & passive & avant-garde & dull & hard & mature \\
\hline 1st K-H-T-P & 2.0 & 2.4 & 1.4 & 1.8 & 1.8 & 2.3 & 1.4 & 1.7 \\
\hline$(S D)$ & $(0.8)$ & $(0.7)$ & $(0.7)$ & $(0.7)$ & $(0.6)$ & $(0.6)$ & $(0.6)$ & $(0.6)$ \\
\hline LMT & 2.0 & 2.5 & 1.3 & 1.9 & 1.6 & 2.5 & 1.2 & 1.8 \\
\hline$(S D)$ & $(0.8)$ & $(0.7)$ & $(0.5)$ & $(0.7)$ & $(0.6)$ & $(0.6)$ & $(0.5)$ & $(0.7)$ \\
\hline Past & 1.6 & 2.4 & 1.3 & 1.7 & 1.9 & 2.2 & 1.4 & 1.5 \\
\hline$(S D)$ & $(0.8)$ & $(0.7)$ & $(0.6)$ & $(0.7)$ & $(0.6)$ & $(0.6)$ & $(0.7)$ & $(0.6)$ \\
\hline 1st Focusing & 1.8 & 1.8 & 1.8 & 1.9 & 2.1 & 2.2 & 1.6 & 1.7 \\
\hline$(S D)$ & $(0.8)$ & $(0.8)$ & $(0.8)$ & $(0.7)$ & $(0.6)$ & $(0.7)$ & $(0.7)$ & $(0.7)$ \\
\hline 2nd Focusing & 1.8 & 1.9 & 1.8 & 1.9 & 2.2 & 2.1 & 1.7 & 1.7 \\
\hline$(S D)$ & $(0.8)$ & $(0.8)$ & $(0.8)$ & $(0.7)$ & $(0.6)$ & $(0.7)$ & $(0.7)$ & $(0.6)$ \\
\hline Future & 2.0 & 2.3 & 1.5 & 1.7 & 2.1 & 2.1 & 1.6 & 1.8 \\
\hline$(S D)$ & $(0.8)$ & $(0.8)$ & $(0.7)$ & $(0.7)$ & $(0.7)$ & $(0.7)$ & $(0.7)$ & $(0.6)$ \\
\hline 2nd K-H-T-P & 2.0 & 2.4 & 1.4 & 1.9 & 1.9 & 2.1 & 1.5 & 1.8 \\
\hline$(S D)$ & $(0.8)$ & $(0.8)$ & $(0.6)$ & $(0.7)$ & $(0.6)$ & $(0.6)$ & $(0.6)$ & $(0.6)$ \\
\hline
\end{tabular}

Level 1: Belonging to life. This level has two subcategories; approachers and avoiders.

Level 2: Belonging to body. This level has the same two subcategories as Level 1.

Level 3: Belonging to society. "Successful." This level has the same two subcategories as the first two.

Level 4 : Belonging to self and "not self." There are no subcategories.

Level 5: Belonging to self and everexpanding "not self." There are no subcategories.

Categorizing judgement of the tests was not easy. Between the two independent judges, the agreement percentages for 56 samples were $42.9 \%$ (house), $51.8 \%$ (tree), $42.9 \%$ (person) on the 1st K-H-T-P, and $37.5 \%$ (house), $51.8 \%$ (tree), $37.5 \%$ (person) on the 2nd K-H-T-P. These percentages were not high. Secondly, each pair of drawings of houses, trees and persons 1 st and 2 nd K-H-T-P were compared according to size (Table 2). The agreements percentages of two independent judges were $91.1 \%$ (house) $60.4 \%$ (tree) and $80.4 \%$ (person). Thirdly, the movement of the person in the drawing was analyzed in terms of three-level scale (Table 2). The standard of movement for 
level 1 was standing; for level 2 walking; and for level 3 running. The agreement percentages of two independent judges were $76.8 \%$ for the 1st K-H-T-P and $83.9 \%$ for the 2 nd K-H-T-P. After a discussion between the two judges, the scoring of all the tests was repeated twice, by one of the judges using a combined judgement. Figure 3 and Figure 4 show relations among three components, that is. house. tree. and person.

\section{Subject's Impressions of Their Pictures}

After drawing each picture, each subject evaluated her own work. The following sixteen three-step scales were used in these selfevauations: (1) past-persent-future, (2) unoriginal-neutral-original, (3) masculine-neutral-femine, (4) like-neutral-dislike, (5) warm-neutral-cool, (6) united-neutral-dispersed, (7) straight-neutral-curvy, (8) moving-neutral-static, (9) flat-neutral-deep, (10) unstable-neutral-stable, (11) light-neutraldark, (12) active-neutral-passive, (13) classic-neutral-avant-garde, (14) sharp-neutraldull, (15) soft-neutral-hard, (16) immatureneutral-mature. Table 3 shows the mean scores and standard deviations of each scale. Subjects liked their own pictures. Their image of their pictures generally seemed to be that they were feminine, warm, light, curvy and soft.

The impressions of the time scale-that is, the past-future scale changed with the time of the drawings. The " $t$ " value between the Past and 1st Focusing scores was $19.8(F=305$, $p<.01)$; between the Past and 2nd Focusing, $21.0(F=305, p<.01)$; between the Past and Future $27.3(F=305, p<.01)$; between the 1st Focusing and Future; between the ist Focusing and Future $12.9(F=305, p<.01)$; and between the 2 nd Focusing and Future, $11.1(F=305, p<.01)$. These " $t$ " values showed significant differences between average scores. As the " $t$ " value between the 1st Focusing and 2nd Focusing was 1.02, there was no significant difference between the two average scores.

Table 4 shows the factor loadings of the scales. Factor 1 was related to "stable" in the plus direction; and to "cool," "hard," and "dark" in the minus direction. This factor reflected warm-cool and soft-hard images

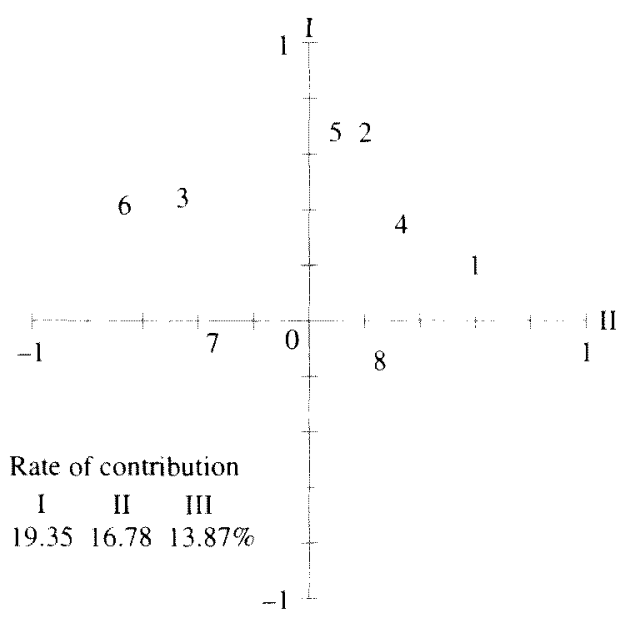

Figure 3. Results of components I and II by principal component analysis for three-step level changes in 1) house, 2) tree, 3) person, 4) size of house, 5) size of tree, 6) size of person, 7) movement and 8) depth of green between ist K-H-T-P and 2nd K-H-T-P.

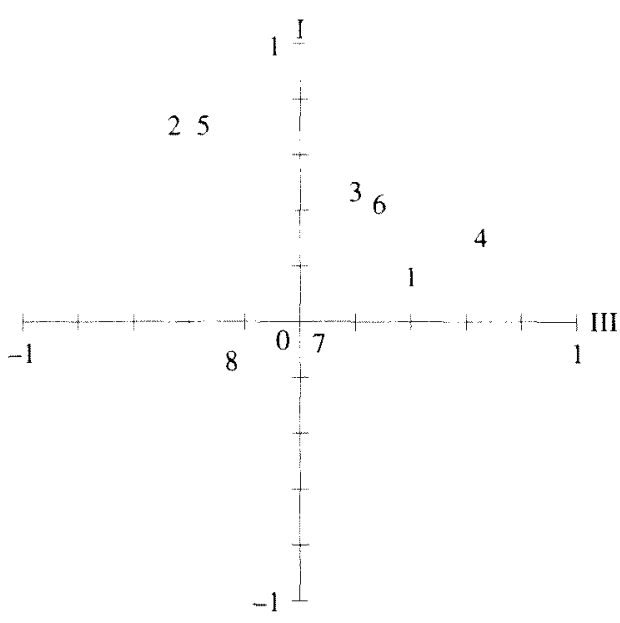

Figure 4. Results of components I and III by pricipal component analysis for three-step level changes in 1) house, 2) tree, 3) person, 4) size of house, 5) size of tree, 6) size of person, 7) movement and 8) depth of green between 1 st K-H-T-P and 2nd K-H-T-P. 
Table 4

Factor loadings of F1, F2, F3 of sixteen scales in the cases of seven kinds of drawings

\begin{tabular}{|c|c|c|c|c|c|c|c|c|c|}
\hline & \multicolumn{3}{|c|}{ K-H-T-P 1st } & \multicolumn{3}{|c|}{ LMT } & \multicolumn{3}{|c|}{ Past } \\
\hline & $\mathrm{Fl}$ & F2 & F3 & $\mathrm{Fl}$ & $\mathrm{F} 2$ & F3 & $\mathrm{Fl}$ & $\mathrm{F} 2$ & F3 \\
\hline future & .09 & .12 & .34 & .07 & .06 & -.00 & .08 & -.22 & -.01 \\
\hline original & -.04 & .42 & .23 & .06 & .37 & .04 & .14 & -.48 & -.22 \\
\hline feminine & .26 & -.15 & -.08 & -.15 & -.17 & -.09 & -.33 & .21 & .30 \\
\hline dislike & -.55 & -.21 & -.18 & .56 & -.26 & -.27 & .22 & .33 & .10 \\
\hline cool & -.81 & .01 & -.02 & .69 & -.08 & .02 & .84 & .06 & .00 \\
\hline dispersed & -.15 & -.02 & -.01 & .49 & -.04 & -.38 & .01 & .02 & -.02 \\
\hline curvy & .20 & .10 &. .02 & -.13 & .12 & .02 & -.23 & -.01 & -.02 \\
\hline static & -.09 & -.60 & .06 & .07 & -.55 & -.10 & .07 & .12 & .92 \\
\hline deep & .05 & .09 & .34 & -.17 & .02 & .43 & .19 & -.21 & -.13 \\
\hline stable & .54 & -.04 & .10 & .67 & -.11 & .19 & -.12 & .01 & -.03 \\
\hline dark & -.72 & -.22 & .10 & .52 & -.22 & .43 & .79 & .05 & .14 \\
\hline passive & -.23 & -.67 & -.05 & .23 & -.65 & .06 & .22 & .48 & .33 \\
\hline avant-garde & -.02 & .50 & .20 & .08 & .34 & .03 & -.15 & -.66 & -.12 \\
\hline dull & .28 & -.34 & -.35 & -.15 &. .43 & -.20 & -.10 & .61 & .18 \\
\hline hard & -.54 & .04 & -.35 & .58 & -.05 & .21 & .56 & -.15 & -.01 \\
\hline mature & .05 & .07 & .44 & -.13 & .09 & .35 & .20 & -.22 & -.11 \\
\hline \multirow[t]{3}{*}{ Rate of contribution } & $14.61 \%$ & $9.41 \%$ & $4.48 \%$ & $14.22 \%$ & $8.44 \%$ & $4.31 \%$ & $12.87 \%$ & $10.08 \%$ & $7.47 \%$ \\
\hline & \multicolumn{3}{|c|}{ Ist Focusing } & \multicolumn{3}{|c|}{ 2nd Focusing } & \multicolumn{3}{|c|}{ Future } \\
\hline & $\mathrm{F} 1$ & $\mathrm{~F} 2$ & F3 & $\mathrm{F} 1$ & $\mathrm{~F} 2$ & F3 & $\mathrm{F} 1$ & $F_{2}$ & F3 \\
\hline future & .02 & .03 & -.16 & .22 & -.10 & -.03 & -.18 & -.05 & -.08 \\
\hline original & -.06 & -.01 & -.27 & .04 & .08 & .03 & -.58 & .20 & .04 \\
\hline feminine & -.10 & .39 & -.01 & -.08 & -.20 & .47 & .30 & -.12 & -.17 \\
\hline dislike & .46 & -.10 & .17 & -.35 & .55 & -.18 & .25 & .24 & .54 \\
\hline $\mathrm{cool}$ & .71 & -.31 & -.03 & -.60 & .30 & -.38 & -.06 & .64 & .18 \\
\hline dispersed & .11 & -.09 & .17 & -.10 & .65 & -.04 & -.03 & .12 & .60 \\
\hline curvy & -.10 & .68 & -.12 & .03 & .05 & .63 & -.05 & .64 & .18 \\
\hline static & .28 & -.05 & .38 & -.43 & -.35 & .05 & .58 & .10 & -.07 \\
\hline deep & -.04 & .06 &. .09 & -.01 & -.08 & .06 & -.17 & .08 & -.30 \\
\hline stable & -.39 & .69 & -.01 & .26 & -.64 & .10 & .13 & -.35 & -.53 \\
\hline dark & .84 & -.11 & .12 & -.73 & .27 & -.15 & .19 & .65 & .13 \\
\hline passive & .50 & .12 & .41 & -.65 & .05 & .07 & .61 & .19 & .13 \\
\hline avant-garde & -.10 & .09 & -.80 & .45 & .04 & -.09 & -.59 & -.06 & -.03 \\
\hline dull & .06 & .46 & .39 & -.30 & -.04 & .39 & .48 & -.06 & -.03 \\
\hline hard & .31 & -.74 & .04 & -.28 & .17 & -.68 & -.06 & .44 & .16 \\
\hline mature & .03 & -.16 & .08 & .10 & -.18 & -.16 & -.11 & .01 & -.16 \\
\hline \multirow[t]{3}{*}{ Rate of contribution } & $12.79 \%$ & $9.71 \%$ & $8.10 \%$ & $13.42 \%$ & $9.66 \%$ & $9.27 \%$ & $11.90 \%$ & $8.40 \%$ & $7.31 \%$ \\
\hline & \multicolumn{3}{|c|}{ 2nd K-H-T-P } & & & & \multicolumn{3}{|c|}{ 2nd K-H-T-P } \\
\hline & $\mathrm{Fl}$ & F2 & F3 & & & & $\mathrm{F} 1$ & F2 & F3 \\
\hline future & -.16 & .12 & -.08 & \multicolumn{3}{|c|}{ stable } & -.36 & -.20 & .58 \\
\hline original & .01 & .26 & -.05 & \multicolumn{3}{|c|}{ dark } & .81 & -.12 & -.07 \\
\hline feminine & -.06 & -.36 & .10 & \multicolumn{3}{|c|}{ passive } & .44 & -.53 & -.13 \\
\hline dislike & .40 & -.08 & -.37 & \multicolumn{3}{|c|}{ avant-garde } & .03 & .40 & .04 \\
\hline cool & .72 & -.05 & .03 & \multicolumn{3}{|c|}{ dull } & -.05 & -.41 & -.11 \\
\hline dispersed & .13 & -.13 & -.74 & \multicolumn{3}{|c|}{ hard } & .39 & .26 & -.10 \\
\hline curvy & -.14 & .04 & .03 & \multicolumn{3}{|c|}{ mature } & .06 & -.04 & .14 \\
\hline static & .16 & -.69 & .09 & \multirow{2}{*}{\multicolumn{3}{|c|}{ Rate of contribution }} & $12.04 \%$ & $9.16 \%$ & $7.17 \%$ \\
\hline deep & .03 & .12 & .06 & & & & & & \\
\hline
\end{tabular}


simultaneously. Here it is callled "expressiveness factor." The 2nd Focusing and "Future" drawings diverged slightly from this trend. The "classic" - "avant-garde" scale seemed to be related to these drawings. Factor 2 was related to "original" and "avantgarde" in the plus direction and to "calm" and "passive" in the minus direction. In the case of the 1st Focusing picture, the directions were reversed. This factor was called the "originality factor." The sclaes of "stable," "deep." and "static" were related to factor 3 on one hand, and "dispersed" and "dislike" scales on the other hand. The former and the latter showed opposite directions in plus or minus in each drawing. This factor seemed to evaluate compositional ability, therefore, it was called the "composition factor." According to their self-evaluations, subjects disliked "dispersed" and "flat" picture. In the 1st Focusing sector if factor 2, and the 2nd Focusing sector of factor 3, the "curvy" and "feminine" scales grouped together and were situated on the opposite side of "hard" scale.

\section{Discussion}

This course took nearly three months including the feedback sessions after the course. In spite of the fact that art therapy was the only activity of the course, the program held the subjects' interest. Their commitement was reflected in the improved scores on the second Aesthetic Interests Test and Self-Esteem Scale. Houses and trees in the 2nd K-H-T-P were drawn larger than in the 1st. These trends suggest an expansion of subjects' self-concepts. However, the house drawings graded down to lower levels during the course. As subjects drew more openly in the 2 nd K-H-T-P than in the $1 \mathrm{st}$, these changes might be due to the roughness of the drawings in the $2 \mathrm{nd}$. The green of the leaves in the tree drawings became deeper as the season changed form spring to summer. These changes paralleled the subjects' rapid development from girls those means fresh green leaves to young women those means ripen deep green leaves.

Subjects' impressions of their pictures seemed to be based on three main factorsexpressiveness, originality, and composition. The expressiveness seems to be the potency factor, originality the activity factor, composition the evaluation factor. The hard-soft and cool-warm scales are generally said to be two independent factors in the study of color; however, in this study these two scales were grouped together because the drawings included color, shape and texture.

The materials of art therapy are generally analyzed by case study methods. In case study, reading the picture and getting insight into the subconsciousness of creater's mind are important task for an art therapist. It is rare that the client gets to the self-insight without help of interpretation of the therapist. On the contrary, the self-evaluation process using three step scales makes it possible for both experimenter and subjects cognitively to read the picture impression from objective point of view.

When a lot of subjects' data like this study are analyzed, statistically oriented analyses are suitable. By the latter methods, effects of the course, successive changes of pictures are globally caught, then the charactors of subjects as a group come to be clear. These results may work as norms to study every case. Burns' five level categories for $\mathrm{K}-\mathrm{H}-\mathrm{T}-\mathrm{P}$ were induced from clinical study. In this study, subjects as a group did not show the significant difference at the first and last of the course. Each case has various changes during the course. But as a group, these changes were erased, and the result showed that their developmental levels were almost unchanged during nine weekly sessions. This is not only negative but also pos- 
itive aspects of nomothetic study.

It is said that the success of a performance depends on how much the performer is able to relax and give full play to his talents. A subject wrote, "I felt good when I heard the word 'Relax!' at the beginning." The course itself was experienced as a kind of relaxation time for art students, who were very busy every day creating works for their regular courses. A second subject wrote, "Recently I haven't had the chance to draw freely, without worrying about evaluation, on the ability and level of my work. Even though I was not so enthusiastic about studying psychological theory, I enjoyed the fresh experiences I had in this course." Similarly, third subject worte, "Expressing directly what I am feeling at the time is very pleasant." The next three from students suggest the therapeutic effects of and the insights about the self that occurred during the course: "I was suprised that I felt so calm while drawing." "I could look at myself from a fresh new perspective." "I realized I had been closed to my feelings."

Regarding the purpose of supporting careers, a subject worte, "I found it easy to show what I was in my mind by drawing concrete objects. Now I feel that I understand what I want. However, I don't have a clear vision of the future yet. I don't know what I should do. I wish to accomplish something, but I don't know how to do it." This comment seemed to represent the situations of most of the subjects.

One of the most interesting findings was that the body images, clothes and hairstyle of the subjects were projected into their pictures. For example, they used the pattern and colors of their clothes in their pictures, horizontal stripes on shirts were projected into pictures as horizontal lines; vertical lines on shirts reappeared on walls in pictures; a pony-tailed young woman drew a pony, so on. Photographs taken during the experiments suggest a relationship between body image and pictures drawn. This will be another subjects for study.

Analyses of each picture will be reported on in other papers. As a way to teach general psychology to art students, this course seemed to succeed in that it retained their interest; however, students wanted more extensive personal feedback. It will be necessary in the future to allow more time for feedback; therefore fewer tasks should be assigned.

\section{References}

Burns, R. C. 1987 Kinetic-House-Tree-Person Drawings ( $\mathrm{K}-\mathrm{H}-\mathrm{T}-\mathrm{P}$ ): An interpretative manual. New York: Brunner-Mazel Publishers.

Caplan, P. J. 1989 Don't blame mother: Mending the mother-daughter relationship. New York: Harper \& Row.

Gendlin, E. T. 1978 Focusing. New York: Bantam Books, Inc.

Lindauer, M. S. 1981 Aesthtic experience: A neglected topic in the psychology of the arts. In D. O'Hare (Ed.), Psychology and the art. Sussex: Harvester Press. Pp. 29-75.

Nakai, H. 1984 H. Nakai Landscape Montage Technique. In Y. Yamanaka (Ed), Series of Hisao Nakai, Annex. Tokyo: Iwasaki Academic Press.

Rosenberg, M. 1965 Society and the adolescent selfimage. Princeton University Press.

Selmen, L. R. 1980 The growth of interpersonal understanding. New York: Academic Press.

(Received Dec. 9, 1991, accepted March 5, 1994) 